\title{
Clonidine in Anesthesiology: A Brief Review
}

\author{
Hermann S Fernandes*, Shirley A Santos and Hazem A Ashmawi \\ Department of Anesthesia, University of São Paulo, Brazil
}

Received: 此 July 19, 2018; Published: 制July 26, 2018

*Corresponding author: Hermann S Fernandes, Divisão de Anestesia, Hospital das Clínicas, University of São Paulo, Avenida Dr. Enéas de Carvalho Aguiar, 255. 8o andar, São Paulo-SP, Brazil, Tel: 5584 988966348; Email: hermann.fernandes@hc.fm.usp.br

\author{
Abstract \\ Background and Aims: The alpha-2-adrenergic mechanism has been explored for a long time in anesthesiology. Clonidine belongs to this class \\ and has some interesting characteristics for this specialty.
}

Contents: This article illustrates pharmacological aspects, mechanisms of action and clinical use of clonidine in anesthesiology. Sedation, analgesia, lower incidence of nausea, opioid needs and adverse effects reduction are some of the beneficial effects of its use. Adverse effects are bradycardia and low blood pressure.

Conclusion: Clonidine reduces post-operative needs of opioid, pain intensity and nausea incidence. However, high risk of perioperative low blood pressure and bradycardia must be taken in consideration when deciding using this drug

\section{Introduction}

From cocaine to dexmedetomidine, passing through noradrenaline, the alpha-2-adrenergic mechanism for analgesia has been explored for more than one century [1]. Although it is known for long time, clonidine, an alpha-2-agonist drug, was used for the first time in human for anesthetics aims only in 1984, epidurally [2]. Since then, several clinical trials, reviews and clinical practice have demonstrated many benefits from the association of clonidine to other anesthetic drugs systemically, spinally or epidurally, with relative safety [1,3-12]. Clonidine has interesting pharmacological characteristics for anesthesia practice, including sedation, hypnosis, analgesia, opioid need reduction and anti-sympathetic response, to surgical trauma response [4].

\section{Contents}

Pharmacological Aspects: Clonidine is an imidazole compound, alpha-adrenergic agonist with selectivity for alpha-2 receptors [13]. It has fast absorption after oral intake, with great biodisponibility. The distribution volume is around $12 \mathrm{~L} /$ $\mathrm{kg}$. It is $50 \%$ metabolized by the liver into inactive compounds. The other half of the drug is eliminated with no changes by the kidney. The elimination half-life may vary when administrated by intravenously, from 6 to 23 hours, depending on kidney function. It has great lipossolubility and crosses the blood brain barrier with no difficulties [14]. The elimination half-life for the spinal administration is shorter: 1,5 hours [1].

\section{Action mechanisms and Effects}

Analgesia: There are alpha-2-agonists receptors in the terminal primary afferent (spinal and peripheral), in spinal superficial lamina neurons and in the supra-spinal nuclei (locus ceruleus) [15]. That way, clonidine and other alpha-2-agonists have analgesic actions on the three sites of sensitive afference: peripheral, spinal and brain. Although there are no such receptors on peripheral nerve axonia, clonidine may increase the effect of local anesthetics in peripheral nerve blocks, by action on $\mathrm{C}$ and $\mathrm{A} \delta$ fibers, decreasing the conduction on those fibers, because of increase of trans-membrane potassium conductance, and through vasoconstrictor effect (alpha1-adrenergic effect), which reduces local anesthetics wash-out from perineural tissues [15-17]. When activated by an agonist agent, alpha-2 receptors inhibit the adenilciclase enzyme, reducing intracellular AMPc, leading to a hyperpolarization membrane state [18]. Inhibition of calcium voltage-dependent channels is another secondary action mechanism of clonidine [14]. Clonidine has a selective affinity to alpha- 2 receptor 220 higher than its affinity to alpha-1 receptor [1].

Hemodynamics: Clonidine has central and peripheral mechanisms for cardiovascular effects. On solitary tract nuclei and on locus ceruleus, the alpha- 2 receptors activation reduces the sympathetic tonus, with inhibition of noradrenaline release on the synaptic junctions, leading to bradycardia and low blood pressure effects [19]. The alpha-2 pre-synaptic receptors on peripheral nerves reduces the noradrenaline exocytosis. In the other hand, post-synaptic alpha-2 receptors stimulation, on endothelium, leads to vasoconstriction, and may cause transitory high blood pressure right after intravenous injection of clonidine [20]. As clonidine is a non-specific selective alpha- 2 agonist, in high doses $(450 \mu \mathrm{g}$, spinal, for example), it may increase blood pressure. This is due to the fact that this drug, in less proportion, also is an alpha-1 agonist [21]. 
Respiratory system: Alpha-2 agonist do not induce deep respiratory depression, even in high doses, nor potentiate respiratory depression caused by opioids [22]. These medications can reverse the muscle stiffness induced by fentanyl, alfentanil, sufentanil and remifentanil [23].

Sedation: Sedation is frequent with clonidine use, in accordance with the sedative and anesthetic-sparing properties that alpha-2agonists present, mainly due to the action of these drugs on the receptors of the locus ceruleus [11].

Kidney Effects: Alpha-2-adrenergic receptors induce diuretic and natriuretic effects in the renal system. Alpha-2 agonist drugs also inhibit the release of the antidiuretic hormone and antagonize its action in the renal tubule. Unlike opioids, they do not present a urinary retention effect [24,25].

Endocrine Effects: Clonidine is a powerful sympatholytic agent. It reduces the secretion of noradrenaline, adrenaline, ACTH, cortisol. It stimulates the release of growth hormone [26]. As a direct effect on the alpha-2 receptors of the pancreatic Langerhans cells, they inhibit insulin secretion, which may increase glycemia, but without relevant clinical consequences [1].

\section{Clonidine uses in anesthesia}

Systemic Use: In anesthesia, clonidine can be used by the oral, intravenous, epidural or intrathecal routes. As a premedication, a dose of 2 to $4 \mu \mathrm{g} / \mathrm{kg}$ orally provides sedation, hypnosis and antisialogogue effect [27]; attenuates perioperative hemodynamic instability, spares need for anesthetics during surgery, and reduces the need for postoperative analgesics $[1,9,10,12,28-30]$. It has a propofol sparing effect, reducing the needs of this venous anesthetic $[8,31]$. In a meta-analysis about systemic clonidine, either orally pre-anesthetic or intraoperative venous administered clonidine, showed that the use of this drug reduces opioid consumption and postoperative pain scores in the first 24 hours, and incidence of nausea in the first 8 hours, but at the expense of lower intraoperative blood pressure levels (not clinically impacting) [4]. Clonidine has been used to attenuate symptoms resulting from withdrawal of opioids, alcohol and benzodiazepines, with encouraging results [32]. Clonidine also has benefit in the treatment of postoperative tremors, with efficacy equivalent to dolantine, but without the adverse effects of this drug [33].

\section{Epidural use}

Epidural clonidine may be used at a dose of 2 to $4 \mu \mathrm{g} / \mathrm{kg}$ and it prolongs the time and improves the quality of analgesia and motor blockade of the associated local anesthetic, with a sedative effect. It can be used continuously at the dose of $30 \mu \mathrm{g} / \mathrm{h}$ [1]. In children, it can be used in sacral epidural block at a dose of 1 to $2 \mu \mathrm{g} / \mathrm{kg}$, which results in a longer duration of postoperative analgesia, without major hemodynamic changes [34]. In the treatment of chronic neoplastic pain, it has already been used epidurally in the dose of $10-50 \mu \mathrm{g} / \mathrm{h}$, when the response to opioids is no longer satisfactory [35].

\section{Spinal use}

At the dose of 1 to $2 \mu \mathrm{g} / \mathrm{kg}$, clonidine has its most pronounced effects when administered intrathecally [1]. As an adjunct to local anesthetics, the drug prolongs sensory and motor blockade without resulting in the typical adverse effects of opioids (urinary retention and respiratory depression, for example) [36,37]. A recent metaanalysis evaluated the efficacy of adding clonidine to morphine in spinal anesthesia in acute postoperative pain and concluded that this drug prolongs the time of analgesia, with a longer time interval for the first analgesic demand and reduces the total dose of morphine used for analgesic rescue [3]. The association of clonidine to spinal local anesthetics has also been the subject of a systematic review, showing that alpha-2-adrenergic agonists increase the duration of motor blockade, improve intraoperative analgesia, and delay motor block regression and the interval for first demand analgesic. The main adverse effect observed is intraoperative hypotension [5].

In obstetrics, the use of clonidine as an adjuvant to cesarean section anesthesia is well established, with several studies showing many benefits. In the immediate postoperative period of patients undergoing cesarean delivery under general anesthesia, $150 \mu \mathrm{g}$ of clonidine alone was administered intrathecally in the immediate postoperative period and compared with placebo, concluding that clonidine induces effective analgesia at this dose for an average of 6 hours, but not without side effects such as hypotension, sedation and dry mouth [38]. Benhamou and colleagues assigned 78 women to undergo cesarean section in groups who received spinal anesthesia with isolated bupivacaine, clonidine $(75 \mu \mathrm{g})$-bupivacaine

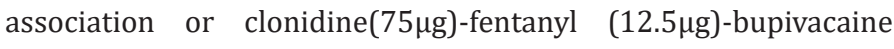
association. After intra and postoperative analysis, the groups receiving clonidine associated with bupivacaine and clonidine associated with fentanyl and bupivacaine showed superior intraoperative analgesia, with no higher frequencies of hypotension, greater need for ephedrine or lower levels of the Apgar score in the newborns. The group receiving bupivacaine, clonidine and fentanyl had better intraoperative analgesia, longer time of postoperative analgesia, and higher sedation rates when compared to the other groups, although this sedation did not exceed moderate levels [39].

The Paech group performed a randomized clinical study on 240 patients and concluded that the subarachnoid combination of $100 \mu \mathrm{g}$ morphine with clonidine for spinal anesthesia in cesarean sections significantly improves postoperative pain relief but increases sedation. He further compared groups with different doses of clonidine, suggesting that the minimum effective dose for spinal clonidine is 30 to $60 \mu \mathrm{g}$, combined with bupivacaine and fentanyl [40]. In Brazil, a recent study by Neves et al. demonstrated that the addition of clonidine to spinal anesthesia with $0.5 \%$ hyperbaric bupivacaine $(12.5 \mathrm{mg})$ and morphine $(100 \mu \mathrm{g})$ for cesarean section improved the quality of postoperative analgesia without increasing the incidence of side effects [41]. In the Netherlands, van Tuijl compared the use of bupivacaine alone to the use of bupivacaine associated with $75 \mu \mathrm{g}$ of clonidine in cesarean spinal anesthesia, concluding that clonidine prolonged the analgesia considerably and improved early analgesia, but there was no difference in total 
consumption of postoperative morphine, only in time to the first demand.

There were no maternal or neonatal side effects [42]. In 2008, Lavand'homme investigated the anti hyperalgesic effects of clonidine. She compared groups of parturients submitted to elective cesarean sections under spinal anesthesia with bupivacaine associated with fentanyl, bupivacaine associated with fentanyl and clonidine, and bupivacaine associated with clonidine. She concluded that the combination of clonidine and spinal bupivacaine had a significant effect on the reduction of the area and the incidence of peri-incisional mechanical hyperalgesia in the first 48 hours of the postoperative period, with no significant side effects [43]. In 2011, Kothari and his co-researchers demonstrated that the $u$ se of clonidine can reduce bupivacaine doses in cesarean section, maintaining adequate motor blockade and prolonging postoperative analgesia, although the use of clonidine has been implicated in higher frequency of certain adverse effects (mild sedation) [44].

\section{Conclusion}

In patients submitted to surgeries under general anesthesia, there is evidence that perioperative use of systemic clonidine (either as a premedication or as an intraoperative adjuvant) reduces postoperative opioid consumption, pain intensity, and incidence of nausea. However, the increased risk of intra- and postoperative hypotension and bradycardia should be taken into account when deciding on the systemic use of this drug. The addition of clonidine to the neuroaxis (intrathecal or epidural) increases the duration of motor blockade, improves the quality of intraoperative analgesia, delays the regression of the sensory blockade, and prolongs postoperative analgesia with later requests for rescue. As with the systemic route, the main intraoperative adverse effect is hypotension.

\section{References}

1. Eisenach JC, De Kock M, Klimscha W (1996) alpha (2)-adrenergic agonists for regional anesthesia. A clinical review of clonidine (19841995). Anesthesiology 85(3): 655-674.

2. Tamsen A, Gordh T (1984) Epidural clonidine produces analgesia. Lancet 2(8396): 231-232.

3. Engelman E, Marsala C (2013) Efficacy of adding clonidine to intrathecal morphine in acute postoperative pain: meta-analysis. British journal of anaesthesia 110(1): 21-27.

4. Blaudszun G, Lysakowski C, Elia N, Tramer MR (2012) Effect of perioperative systemic alpha2 agonists on postoperative morphine consumption and pain intensity: systematic review and meta-analysis of randomized controlled trials. Anesthesiology 116(6): 1312-1322.

5. Elia N, Culebras X, Mazza C, Schiffer E, Tramer MR (2008) Clonidine as an adjuvant to intrathecal local anesthetics for surgery: systematic review of randomized trials. Regional anesthesia and pain medicine 33(2): 159167.

6. Roelants F (2006) The use of neuraxial adjuvant drugs (neostigmine, clonidine) in obstetrics. Current opinion in anaesthesiology 19(3): 233237.

7. Yanagidate F, Hamaya Y, Dohi S (2001) Clonidine premedication reduces maternal requirement for intravenous morphine after cesarean delivery without affecting newborn's outcome. Regional anesthesia and pain medicine 26(5): 461-467.

8. Fehr SB, Zalunardo MP, Seifert B, Rentsch KM, Rohling RG, et al. (2001) Clonidine decreases propofol requirements during anaesthesia: effect on bispectral index. British journal of anaesthesia 86(5): 627-632.

9. Goyagi T, Tanaka M, Nishikawa T (1998) Oral clonidine premedication enhances postoperative analgesia by epidural morphine. Anesthesia and analgesia 89(6): 1487-1491.

10. Benhamou D, Narchi P, Hamza J, Marx M, Peyrol MT, et al. (1994) Addition of oral clonidine to postoperative patient-controlled analgesia with i.v. morphine. British journal of anaesthesia 72(5): 537-540.

11. Maze M, Tranquilli W (1991) Alpha-2 adrenoceptor agonists: defining the role in clinical anesthesia. Anesthesiology 74(3): 581-605.

12. Richards MJ, Skues MA, Jarvis AP, Prys Roberts C (1990) Total i.v. anaesthesia with propofol and alfentanil: dose requirements for propofol and the effect of premedication with clonidine. British journal of anaesthesia 65(2): 157-163.

13. Khan ZP, Ferguson CN, Jones RM (1999) alpha-2 and imidazoline receptor agonists. Their pharmacology and therapeutic role. Anaesthesia 54(2): 146-165.

14. Hayashi Y, Maze M (1993) Alpha 2 adrenoceptor agonists and anaesthesia. British journal of anaesthesia 71(1): 108-118.

15. Unnerstall JR, Kopajtic TA, Kuhar MJ (1984) Distribution of alpha 2 agonist binding sites in the rat and human central nervous system: analysis of some functional, anatomic correlates of the pharmacologic effects of clonidine and related adrenergic agents. Brain research 319(1): 69-101.

16. Gaumann DM, Brunet PC, Jirounek P (1994) Hyperpolarizing afterpotentials in $\mathrm{C}$ fibers and local anesthetic effects of clonidine and lidocaine. Pharmacology 48(1): 21-29.

17. Gaumann DM, Brunet PC, Jirounek P (1992) Clonidine enhances the effects of lidocaine on C-fiber action potential. Anesthesia and analgesia 74(5): 719-725.

18. Nacif Coelho C, Correa Sales C, Chang LL, Maze M (1994) Perturbation of ion channel conductance alters the hypnotic response to the alpha 2 -adrenergic agonist dexmedetomidine in the locus coeruleus of the rat. Anesthesiology 81(6): 1527-1534.

19. De Vos H, Bricca G, De Keyser J, De Backer JP, Bousquet P, et al. (1994) Imidazoline receptors, non-adrenergic idazoxan binding sites and alpha 2 -adrenoceptors in the human central nervous system. Neuroscience 59(3): 589-598.

20. Langer SZ, Duval N, Massingham R (1985) Pharmacologic and therapeutic significance of alpha-adrenoceptor subtypes. Journal of cardiovascular pharmacology 7 Suppl 8: S1-S8.

21. Frisk Holmberg M, Paalzow L, Wibell L (1984) Relationship between the cardiovascular effects and steady-state kinetics of clonidine in hypertension. Demonstration of a therapeutic window in man. European journal of clinical pharmacology 26(3): 309-313.

22. Bailey PL, Sperry RJ, Johnson GK, Eldredge SJ, East KA, et al. (1991) Respiratory effects of clonidine alone and combined with morphine, in humans. Anesthesiology 74(1): 43-48.

23. Weinger MB, Segal IS, Maze M (1989) Dexmedetomidine, acting through central alpha-2 adrenoceptors, prevents opiate-induced muscle rigidity in the rat. Anesthesiology 71(2): 242-249.

24. Mizobe T, Maze M (1995) Alpha 2-adrenoceptor agonists and anesthesia. International anesthesiology clinics 33(1): 81-102.

25. Smyth DD, Umemura S, Pettinger WA (1985) Alpha 2-adrenoceptor antagonism of vasopressin-induced changes in sodium excretion. The American journal of physiology 248(6 Pt 2): 767-772. 
26. Muzi M, Goff DR, Kampine JP, Roerig DL, Ebert TJ (1992) Clonidine reduces sympathetic activity but maintains baroreflex responses in normotensive humans. Anesthesiology 77(5): 864-871.

27. Carabine UA, Wright PM, Moore J (1991) Preanaesthetic medication with clonidine: a dose-response study. British journal of anaesthesia 67(1): 79-83.

28. Flacke JW, Bloor BC, Flacke WE, Wong D, Dazza S, et al. (1987) Reduced narcotic requirement by clonidine with improved hemodynamic and adrenergic stability in patients undergoing coronary bypass surgery. Anesthesiology 67(1): 11-19.

29. Ghignone M, Quintin L, Duke PC, Kehler CH, Calvillo O (1986) Effects of clonidine on narcotic requirements and hemodynamic response during induction of fentanyl anesthesia and endotracheal intubation. Anesthesiology 64(1): 36-42.

30. Segal IS, Jarvis DJ, Duncan SR, White PF, Maze M (1991) Clinical efficacy of oral-transdermal clonidine combinations during the perioperative period. Anesthesiology 74(2): 220-225.

31. Ghosh I, Bithal PK, Dash HH, Chaturvedi A, Prabhakar H (2008) Both clonidine and metoprolol modify anesthetic depth indicators and reduce intraoperative propofol requirement. Journal of anesthesia 22(2): 131 134.

32. Strobbe S, Brower KJ, Galen LW (2003) Predicting completion of outpatient opioid detoxification with clonidine. The American journa on addictions / American Academy of Psychiatrists in Alcoholism and Addictions 12(3): 260-269.

33. Hommeril JL, Bernard JM, Passuti N, Pinaud M, Souron R (1991) [Effects of intravenous clonidine on postoperative shivering]. Annales francaises d'anesthesie et de reanimation 10(6): 554-558.

34. Jamali S, Monin S, Begon C, Dubousset AM, Ecoffey C (1994) Clonidine in pediatric caudal anesthesia. Anesthesia and analgesia 78(4): 663-666.

35. Eisenach JC, DuPen S, Dubois M, Miguel R, Allin D (1995) Epidural clonidine analgesia for intractable cancer pain. The Epidural Clonidine Study Group. Pain 61(3): 391-399.

\section{ISSN: 2574-1241}

DOI: 10.26717/BJSTR.2018.07.001481

Hermann S Fernandes. Biomed J Sci \& Tech Res

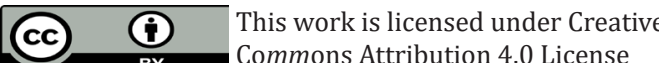

Submission Link: https://biomedres.us/submit-manuscript.php
36. Gentili M, Bonnet F (1996) Spinal clonidine produces less urinary retention than spinal morphine. British journal of anaesthesia 76(6): 872-873.

37. Fogarty DJ, Carabine UA, Milligan KR (1993) Comparison of the analgesic effects of intrathecal clonidine and intrathecal morphine after spinal anaesthesia in patients undergoing total hip replacement. British journal of anaesthesia 71(5): 661-664.

38. Filos KS, Goudas LC, Patroni O, Polyzou V (1992) Intrathecal clonidine as a sole analgesic for pain relief after cesarean section. Anesthesiology 77(2): 267-274.

39. Benhamou D, Thorin D, Brichant JF, Dailland P, Milon D, et al. (1998) Intrathecal clonidine and fentanyl with hyperbaric bupivacaine improves analgesia during cesarean section. Anesthesia and analgesia 87(3): 609-613.

40. Paech MJ, Pavy TJ, Orlikowski CE, Yeo ST, Banks SL, et al. (2004) Postcesarean analgesia with spinal morphine, clonidine, or their combination. Anesthesia and analgesia 98(5): 1460-1466.

41. Neves JF, Monteiro GA, Almeida JR, Sant anna RS, Saldanha RM, et al. (2006) [Postoperative analgesia for cesarean section: does the addiction of clonidine to subarachnoid morphine improve the quality of the analgesia?]. Revista brasileira de anestesiologia 56(4): 370-376.

42. Van Tuijl I, van Klei WA, van der Werff DB, Kalkman CJ (2006) The effect of addition of intrathecal clonidine to hyperbaric bupivacaine on postoperative pain and morphine requirements after Caesarean section: a randomized controlled trial. British journal of anaesthesia 97(3): 365370 .

43. Lavand homme PM, Roelants F, Waterloos H, Collet V, De Kock MF (2008) An evaluation of the postoperative antihyperalgesic and analgesic effects of intrathecal clonidine administered during elective cesarean delivery. Anesthesia and analgesia 107(3): 948-955.

44. Kothari N, Bogra J, Chaudhary AK (2011) Evaluation of analgesic effects of intrathecal clonidine along with bupivacaine in cesarean section. Saudi journal of anaesthesia 5(1): 31-35.

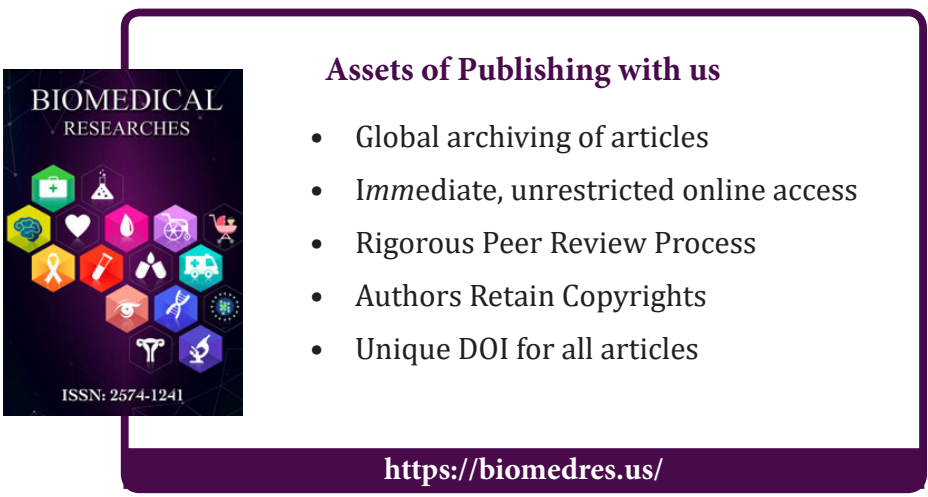

